\title{
Influence of dentin thickness on intrapulpal temperature under simulated pulpal pressure during Nd:YAG laser irradiation
}

\author{
L. R. Santis ${ }^{1}$ - T. M. Silva ${ }^{1}$ • B. A. Haddad ${ }^{1}$ - L. L. Gonçalves ${ }^{1}$ - S. E. P. Gonçalves ${ }^{1}$
}

Received: 22 July 2016 / Accepted: 13 October 2016/Published online: 24 October 2016

(C) Springer-Verlag London 2016

\begin{abstract}
The aim of this study was to evaluate the effects of dentin thickness and pulpal pressure simulation (PPS) on the variation of intrapulpal temperature $(\Delta \mathrm{T})$ when submitted to an adhesive technique using laser irradiation. Sixty sound human molars were sectioned and randomly divided into two groups $(n=30)$ : group $1-1 \mathrm{~mm}$ of dentin thickness; group $2-2 \mathrm{~mm}$ of dentin thickness. Each group was divided into two subgroups $(n=15)$ : subgroup A-absence of PPS; subgroup $\mathrm{P}$ - presence of PPS $\left(15 \mathrm{~cm} \mathrm{H}_{2} \mathrm{O}\right)$, sequentially treated with the following: $37 \%$ phosphoric acid, adhesive system (Adper Single Bond), irradiation with Nd:YAG laser $(1064 \mathrm{~nm}, 10 \mathrm{~Hz}, 60 \mathrm{~s})$ using 60, 80, and $100 \mathrm{~mJ} /$ pulse energy parameters and light-curing $(10 \mathrm{~s})$. The $\Delta \mathrm{T}$ was evaluated during the laser irradiation with a digital thermometer. Data were analyzed by three-way ANOVA and Tukey tests $(p<0.05)$. Three-way ANOVA revealed no significant differences for dentin thickness $(p=0.6512)$ on $\Delta$ T. PPS significantly reduced $\Delta \mathrm{T}(p=0.0001)$. The laser energy parameters
\end{abstract}

T. M. Silva

tania.silva@ict.unesp.br; taniamara.odonto@gmail.com

L. R. Santis

leandrosantis@gmail.com

B. A. Haddad

bruno_haddad@hotmail.com

L. L. Gonçalves

dralucelialemes@hotmail.com

S. E. P. Gonçalves

sergio@ict.unesp.br

1 Department of Restorative Dentistry, Institute of Science and Technology of São José dos Campos, UNESP - Univ Estadual Paulista, Av. Engenheiro Francisco José Longo, 777, Jardim São Dimas, São José dos Campos 12245-000, SP, Brazil $(p=0.0027)$ indicated that $100 \mathrm{~mJ}$ presented with significantly greater $\Delta \mathrm{T}$ when compared to the groups irradiated with 80 and $60 \mathrm{~mJ}$. Dentin thickness did not affect $\Delta \mathrm{T}$. The presence of PPS reduced the mean temperature values. The Nd:YAG laser energy parameters had a negative influence on the variation of temperature in the absence of PPS. In the presence of PPS, there was no risk to the pulp, since this study obtained temperature increases below $5.5{ }^{\circ} \mathrm{C}$ for all energy parameters, showing the technical viability for in vivo conditions.

Keywords Intrapulpal pressure $\cdot$ Temperature $\cdot \mathrm{Nd}$ :YAG laser $\cdot$ Dentin

\section{Introduction}

Different types of lasers are used as alternatives for enhancing the adhesion pattern between a restorative material and dental substrate, including Nd:YAG (neodymium yttrium aluminum garnet), Er:YAG (erbium), Ho:YAG (holmium), $\mathrm{CO}_{2}$ and, more recently, ErCr:YSGG lasers [1-4].

Due to higher applicability, the neodymium laser is used to remodel soft tissue and provide coagulation [5], modify enamel and dentin surfaces [5], and for dentin desensitization [6, 7]. The first application of Nd:YAG laser was performed prior to applying the adhesive system, which resulted in a reduction in bond strength when compared to non-irradiated surfaces. This occurred because Nd:YAG laser causes denaturation of the organic components in dentin due to heat generation, obliteration of dentin tubules, and recrystallization of the inorganic components $[3,8,9]$.

Given these observations, Gonçalves and others [1] evaluated the irradiation of neodymium laser on dentin after etching and applying the adhesive system. Those authors showed the fusion and recrystallization of dentin in the presence of resin 
monomers, which resulted in greater bond strength. Several studies also showed satisfactory results regarding this adhesive technique $[2,8,10-12]$.

However, the effects of laser on the dentin substrate might be influenced by the thickness of dentin, surface cooling, and laser parameters. In 2016, Silva et al. [12] evaluated the variation of temperature during laser irradiation under simulated pulpal pressure. Those authors observed a reduction in the variation of temperature in the presence of simulated pulpal pressure and an increase in temperature with rising laser parameters, with minor surface variations when irradiated with 100,80 , and $60 \mathrm{~mJ}$. Therefore, the thermal effect during laser irradiation is still unknown when considering the thickness of dentin, a relevant factor for the adhesive technique proposed by Gonçalves and others [1].

Furthermore, the dentin substrate has a structural variability with a dense network of tubules providing communication with the pulp chamber. The density, diameter, and orientation of tubules vary according to the depth, as the quantity and diameter of tubules increases towards the pulp. In depth, the quality of dentin also changes, reducing the mineralization of the intertubular matrix [1, 13-15]. The dentinal tubules are filled with interstitial fluid that moves through the tubules by capillary action, driven by hydrostatic intrapulpal pressure, favoring the wettability of the dentin surface [16].

Therefore, the amount of heat generated during laser irradiation and conducted to the pulp chamber depends on the thickness of dentin and the presence of a pulpal pressure, since the Nd:YAG laser tips do not have an associated cooling system associated with it. Consequently, the temperature increase based on the depth of the remaining dentin must be controlled in order to maintain the irradiated and adjacent tissues.

The aim of this study was to evaluate the effects of dentin thickness associated with pulpal pressure simulation (PPS) on the variation of intrapulpal temperature $(\Delta \mathrm{T})$ when submitted to an adhesive technique using laser irradiation. The null hypotheses tested were (1) the thickness of dentin does not significantly influence the pulp temperature during laser irradiation; (2) pulpal pressure simulation during laser irradiation does not result in a significant influence on the temperature on the pulp chamber; and (3) changes in Nd:YAG laser energy parameters do not result in a significant influence on the intrapulpal temperature.

\section{Materials and methods}

\section{Specimen preparation}

Sixty maxillary and mandibular sound human molars that were extracted for therapeutic reasons under approval of the Research Ethical Committee at the São José dos Campos School of Dentistry (Protocol number 283.030) were used in this study. The teeth were cleaned using periodontal curetes (Gracey Millennium, Golgran, São Caetano do Sul, SP, Brazil) and stored in deionized water at $4{ }^{\circ} \mathrm{C}$, for a period of no more than 30 days [17].

The teeth were fixed in an acrylic holder (Jet, Artigos Odontológico Clássico, Campo Limpo Paulista, SP, Brazil) $(2.5 \mathrm{~cm}$ diameter and $2.0 \mathrm{~cm}$ high) using dental wax (Lysanda, São Paulo, SP, Brazil). The teeth were sectioned parallel to the occlusal surface to expose dentin and $1.0 \mathrm{~mm}$ below the enamel-cementum junction to separate the crown from the roots, using a low-speed laboratory cutting machine (Labcut 1010, Extec Technologies Inc., Enfield, CT, USA), under water cooling.

The dentin specimens were polished using 600-grit aluminum oxide abrasive disks (Extec Corp., Enfield, CT, USA) in a polishing device (DP-10, Panambra, São Paulo, SP, Brazil), under water cooling, to standardize 30 samples with approximately $1.0 \mathrm{~mm}$ of dentin thickness, and the remaining 30 with approximately $2.0 \mathrm{~mm}$ thickness from the highest pulp horn, measured with a caliper (Otto-Arminger \& Cia Ltda, Brusque, SC, Brazil).

In sequence, the dentin specimens ( 30 samples of $1.0 \mathrm{~mm}$ thickness and 30 samples of $2.0 \mathrm{~mm}$ thickness) were randomly divided into two subgroups ( $n=15$ ), according to the treatments: with or without PPS. Each group was divided into other three subgroups $(n=5)$, based on Nd:YAG laser energy parameters: 60,80 , and $100 \mathrm{~mJ}$.

\section{Intrapulpal pressure simulation}

For the group submitted to pulpal pressure simulation, selfcured acrylic resin holders (Jet, Artigos Odontológico Clássico, Campo Limpo Paulista, SP, Brazil) were constructed measuring $1.5 \mathrm{~cm} \times 1.5 \mathrm{~cm} \times 0.5 \mathrm{~cm}$. In these holders, three holes (two holes to simulate water fluid flow inside the pulp chamber and one hole to install the thermocouple inside the highest pulp horn) were done [12].

Two hypodermic needles (Injex, Ourinhos, SP, Brazil) $(0.7 \times 10 \mathrm{~mm})$ were positioned into the center of the acrylic holder, perpendicular to its base. The first needle was positioned so that its upper tip communicated with the pulp chamber and its lower tip was linked to a hydrostatic pressure device [6]. The second needle was placed so that its upper tip was inside the pulp chamber and the lower tip linked to silicone tubes (Mark Med Ind. LTDA, Bragança Paulista, SP, Brazil), enabling water fluid to flow towards the other reservoir (Fig. 1).

The device for intrapulpal pressure simulation had a reservoir filled with deionized water at $37{ }^{\circ} \mathrm{C}[6,18,19]$, placed $15 \mathrm{~cm}$ above the level of the pulp chamber [20]. Before simulated pulpal pressure, deionized water was injected into the pulp chamber to avoid bubbles inside the chamber and to assure its total filling by the liquid. 
Fig. 1 Representative scheme of pulpal pressure simulation

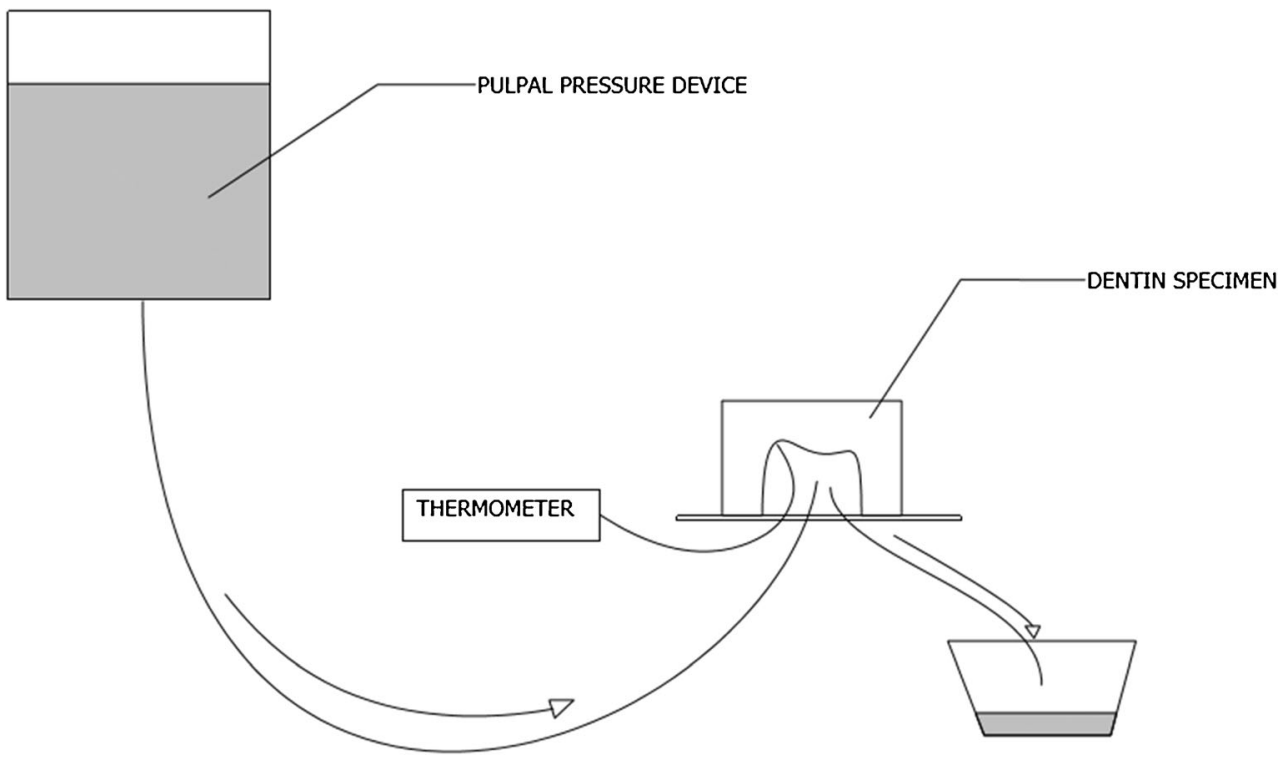

\section{Adhesive procedure and Nd:YAG laser irradiation}

The dentin surfaces were etched with $37 \%$ phosphoric acid (Magic Acid, Coltene Vigodent SA Indústria e Comércio, Rio de Janeiro, RJ, Brazil) for $15 \mathrm{~s}$ and rinsed for $30 \mathrm{~s}$. To remove excess water, the surface was gently dried with brief jets of air. The adhesive system (Adper Single Bond 2, 3M ESPE Dental Products, Saint Paul, MN, USA) was applied according to the manufacturer's instructions. Before light curing, the specimens impregnated with non-polymerized adhesive system were irradiated with Nd:YAG laser (neodymium: yttrium-aluminum-garnet) Pulse Master 600 IQ (American Dental Technologies, Corpus Christi, TX, USA), at a wavelength of $1064 \mathrm{~nm}$ and a $320-\mu \mathrm{m}$ diameter optical fiber. A frequency of $10 \mathrm{~Hz}$ was applied using different energy parameters:

- $60 \mathrm{~mJ}$ : tissue irradiation with Nd:YAG laser using $60 \mathrm{~mJ} /$ pulse and $75 \mathrm{~J} / \mathrm{cm}^{2}$ energy density;

- $80 \mathrm{~mJ}$ : tissue irradiation with Nd:YAG laser using $80 \mathrm{~mJ} /$ pulse and $99 \mathrm{~J} / \mathrm{cm}^{2}$ energy density;

- $100 \mathrm{~mJ}$ : tissue irradiation with Nd:YAG laser using $100 \mathrm{~mJ} /$ pulse and $124 \mathrm{~J} / \mathrm{cm}^{2}$ energy density.

Laser irradiation was performed in non-contact mode and surface scanning for $60 \mathrm{~s}$. During irradiation, the laser fiber tip was positioned perpendicular to the specimen surface and at a distance of approximately $1 \mathrm{~mm}$. All laser irradiation was performed by the same calibrated operator.

After laser irradiation, the adhesive system was light cured (LED Light Curing System, Demi Plus, Kerr Corporation, Middleton, WI, USA), with a power density of $1200 \mathrm{~mW} /$ $\mathrm{cm}^{2}$, for $10 \mathrm{~s}$.

\section{Temperature measurement}

To measure the intrapulpal temperature, a digital thermometer with a type K thermocouple sensor (MT-507, Minipa Indústria e Comércio Ltda., São Paulo, SP, Brazil) was used. The thermometer monitored the temperature inside the pulp chamber during laser irradiation. The initial measurement was performed before irradiation $\left(T_{\text {initial }}\right)$, and the maximum temperature peaks $\left(T_{\max }\right)$ were registered during the first $60 \mathrm{~s}$ of laser irradiation.

For the group submitted to intrapulpal pressure simulation, the specimens were fixed into the holders to simulate pulpal pressure and the thermometer was placed below the roof of the pulp chamber of the highest horn and in contact with the dentin.

For the group without intrapulpal pressure simulation, the pulp chamber was filled with thermal paste (Implastec, Tietê, SP, Brazil) [19, 21]. The thermometer was positioned in contact with the dentin in the highest pulp horn. This enabled the determination of temperature inside the pulp chamber without the interferences of the external medium.

\section{Statistical analysis}

Concerning the variation of temperature, in degrees Celsius $\left({ }^{\circ} \mathrm{C}\right)$ obtained during laser irradiation, the differences between the maximum value and the initial (before laser irradiation) was calculated, according to the formula $\Delta T=\mathrm{T}_{\max }-T_{\text {initial }}$.

Data analysis was carried out using the software program Minitab for Windows (version 16.1, College State, PA, USA), Statistica for Windows (version 9.1, StatSoft Inc., Tulsa, OK, USA) and Statistix 9 (version 9.1, Tallahassee, FL, USA). As data were normally distributed (Anderson-Darling, Minitab), statistical analysis were submitted to three-way analysis of 
variance (ANOVA; dentin thickness, intrapulpal pressure, and laser energy parameters) and Tukey tests, with the power study around $80 \%$ for the significance level set at $5 \%$ $(p<0.05)$.

\section{Results}

According to the three-way ANOVA, the dentin thickness showed no significant difference $(p=0.6512)$ on the variation of intrapulpal temperature (Table 1). The presence of intrapulpal pressure significantly reduced $(p=0.0001)$ the variation of intrapulpal temperature when compared with the group without intrapulpal pressure simulation. When considering laser energy parameters $(p=0.0027), 100 \mathrm{~mJ}$ of laser irradiation showed significantly greater variation of temperature when compared to the groups irradiated with 80 and $60 \mathrm{~mJ}$ in the absence of intrapulpal pressure simulation.

When considering the interaction of laser energy parameters and intrapulpal pressure $(p=0.0001)$, the lowest variation of temperature means were observed in the groups irradiated with 60 and $80 \mathrm{~mJ}$ with the presence of intrapulpal pressure, which differed significantly from the other groups. The interaction between dentin thickness and intrapulpal pressure $(p=$ 0.0009 ) showed the lowest variation of temperature means in groups with intrapulpal pressure simulation, which differed significantly from groups with the absence of pulpal pressure simulation (Table 2).

\section{Discussion}

The present study analyzed the adhesive technique proposed by Gonçalves and others [1], to evaluate the variation of temperature during the irradiation of Nd:YAG laser in 1 and $2 \mathrm{~mm}$ of dentin thickness, in the presence and absence of PPS, with the aim of determining the thermal damage that the laser

Table 1 Three-way ANOVA for the variation of intrapulpal temperature

\begin{tabular}{llllll}
\hline Source & DF & SS & MS & F & $p$ \\
\hline Laser & 2 & 0.17272 & 0.08636 & 6.70 & $0.0027^{*}$ \\
Pulpal pressure (PP) & 1 & 5.39000 & 5.39000 & 417.92 & $0.0001^{*}$ \\
Thickness (T) & 1 & 0.00267 & 0.00267 & 0.21 & 0.6512 \\
Laser $\times$ PP & 2 & 0.42673 & 0.21337 & 16.54 & $0.0001^{*}$ \\
Laser $\times \mathrm{T}$ & 2 & 0.01743 & 0.00871 & 0.68 & 0.5136 \\
$\mathrm{PP} \times \mathrm{T}$ & 1 & 0.16252 & 0.16252 & 12.60 & $0.0009^{*}$ \\
Laser $\times \mathrm{PP} \times \mathrm{T}$ & 2 & 0.02083 & 0.01041 & 0.81 & 0.4519 \\
Error & 48 & 0.61907 & 0.01290 & & \\
Total & 59 & 6.81197 & & & \\
\hline
\end{tabular}

*Statistically significant differences $(p<0.05)$ would produce when used in vivo. The results showed the greatest variation of temperature in the absence of PPS independent of the remaining dental thicknesses.

White and others [18] demonstrated that temperature increases during laser irradiation may damage pulp tissues when the remaining dentin tissue is less than $1 \mathrm{~mm}$ thick. According to other study [19], thermal analyses must consider the anatomical structures of remaining dentin because different topographies result in different rates of heat exchange. These observations led us to standardize the remaining dentin from the highest pulp horn [22], to avoid differences in the results due to morphological variations of dentin and to define the same site at the same depth where the thermometer was placed.

The main advantage of using human dentin is due to similarities with in vivo conditions [23]. Dentin has a wide chemical and physical variability in its composition with regard to presence of organic and inorganic components; different ratios of peritubular, intertubular, and sclerotic dentin; and variation in permeability and communication with the pulp. Moreover, previous studies have evaluated the variation of temperature inside of pulp chambers of human teeth [6, 19, 21, 24]. In the current study, medium $(2 \mathrm{~mm})$ and deep $(1 \mathrm{~mm})$ dentin thicknesses were evaluated and the variation of temperature $(\Delta T)$ in the experimental conditions did not show significant differences.

Our results corroborate with the studies of White and others [18], who presented higher temperature changes in remaining dentin thicknesses smaller than $1 \mathrm{~mm}$. Other previous study [25] reported that 2 and $3 \mathrm{~mm}$ of dentin thickness did not show significant differences in temperature, and the lowest temperature changes were observed with $4 \mathrm{~mm}$ of dentin thickness. Despite the anatomical variability, 1 and $2 \mathrm{~mm}$ of dentin thickness suffered few variations of temperature during Nd:YAG laser irradiation. The results of this study showed that the thickness of dentin was not statistically significant on the variation of temperature (Table 1). Therefore, the first null hypothesis - the thickness of dentin does not significantly influence the pulp temperature during laser irradiation-was accepted.

The dentin tubules are filled with fluid that moves through the tubules using capillary action, driven by hydrostatic intrapulpal pressure. Dentin surface wettability and the presence of intrapulpal pressure are the critical variables during adhesive procedures. Therefore, this in vitro study applied the hydrostatic pulpal pressure using a $15-\mathrm{cm}$ column of deionized water $[20,22,26]$, simulating in vivo conditions.

PPS interfered significantly in the variation of temperature of this study, reducing approximately $80 \%$ of temperature when compared to the groups without PPS. The groups submitted to PPS showed no significant differences among the laser energy parameters. However, when considering the groups without PPS, the energy parameter of $100 \mathrm{~mJ}$ 
Table 2 Means $( \pm \mathrm{SD})$ of the variation of intrapulpal temperature $(\Delta \mathrm{T})$ and the Tukey results $(5 \%)$ for all groups

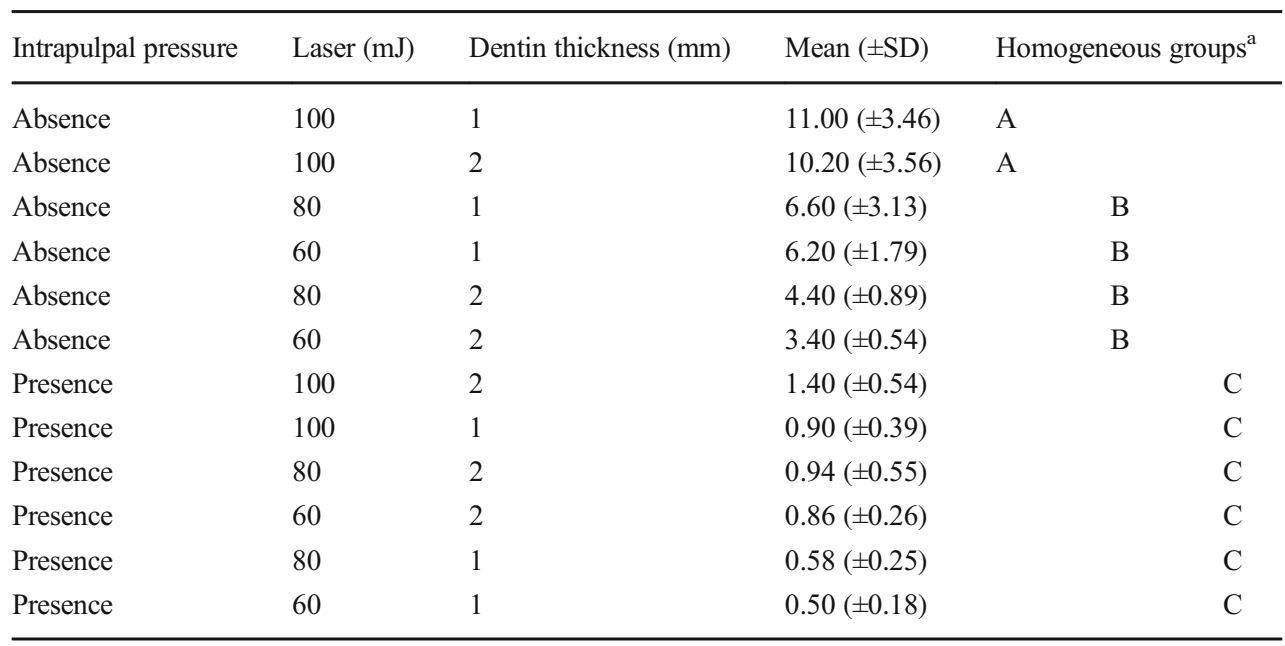

${ }^{a}$ The means followed by the same letter did not show statistically significant differences provoked $\Delta \mathrm{T}$ means $\left(1 \mathrm{~mm}=11.00 \pm 3.46^{\mathrm{A}} ; 2 \mathrm{~mm}=10.20 \pm\right.$ $3.46^{\mathrm{A}}$ ) that were significantly higher than the energy parameters of 80 and $60 \mathrm{~mJ}$. The highest $\Delta \mathrm{T}$ mean was observed in the absence of PPS conditions, similar to Secilmis and others [25].

The results of the current study are in agreement with other similar studies [12,25], which demonstrated that the presence of liquid and the fluid flow allowed heat dissipation by renewing the liquid inside the pulp chamber. The pulpal pressure simulation plays a fundamental role on in vitro tests with the aim of approaching in vivo conditions in the adhesion of restorative materials and the biological effect on the pulp tissues $[12,27]$. Therefore, the second null hypothesis - pulpal pressure simulation during laser irradiation does not result in a significant influence on the temperature on the pulp chamber-was rejected.

Given the literature, in vitro and in vivo temperature evaluations are still controversial. In vivo intrapulpal temperature increases might be lower than those obtained with in vitro studies, due to the presence of an intact periodontal ligament, cortical bone, and pulpal blood flow, which reduces temperature increases [28]. Despite the controversies between the critical temperature to avoid damage to the pulp and periodontal tissue, this study considered $5.5^{\circ} \mathrm{C}$ as the boundary temperature $[6,18,19,24,25]$.

The energy parameters of 60,80 , and $100 \mathrm{~mJ}$ irradiated on dentin surface demonstrated smaller variation of temperature in the presence of PPS in a previous study [12] enabling the adhesive technique proposed by Gonçalves and others [1] without causing damage to tissues. Nd:YAG laser causes denaturation of the organic dentin components due to heat generation, obliteration of dentin tubules due to fusion and recrystallization of the inorganic components [11, 29]. When the laser is used in adhesive procedures on a dentin substrate, the intrapulpal temperature increases are directly proportional to the applied laser energy and the irradiation time. Goodis and others [6] verified that temperature increases cause damage in pulp tissue when laser was applied for 2 min of irradiation. Those authors recommended shorter periods of irradiation during treatment. In the present study, we standardized a minor irradiation time (60 s) in accordance with other studies that suggested the methodology proposed [11, 12].

In addition to the exposure time, previous studies [30,31] showed temperature increases based on increasing energy density $\left(\mathrm{J} / \mathrm{cm}^{2}\right)$. The energy density of the current study varied according to the energy parameters applied $\left(60 \mathrm{~mJ}=75 \mathrm{~J} / \mathrm{cm}^{2}\right.$; $80 \mathrm{~mJ}=99 \mathrm{~J} / \mathrm{cm}^{2} ; 100 \mathrm{~mJ}=124 \mathrm{~J} / \mathrm{cm}^{2}$ ). The laser energy densities are also dependent on the diameter of optical fiber used [26]. In this study, we used a 320- $\mu$ m diameter optical fiber in accordance with other studies that have adopted the methodology proposed by Gonçalves and others $[2,11]$.

However, a study of Silva et al. [12] used a 400- $\mu \mathrm{m}$ diameter optical fiber to evaluate intrapulpar temperature. Despite lower energy densities generated by the larger caliber fiber, the authors reported higher $\Delta \mathrm{T}$ means than those in our results. This fact may have been due to differences in morphological structures of teeth, different operator characteristics, and particular conditions during execution that represent limitation of the study and comparison among studies.

In this current study, all energy parameters used in the presence of PPS exhibited $\Delta \mathrm{T}$ mean below $5.5^{\circ} \mathrm{C}$, regardless of the dentin thickness, ensuring safe energy parameters of laser for making changes on the surface without causing damage to the surrounding tissues. On the other hand, the energy parameters in the absence of PPS showed $\Delta \mathrm{T}$ mean above $5.5^{\circ} \mathrm{C}$ at $1 \mathrm{~mm}$ of dentin thickness, as shown in Table 2 . In the condition without PPS, the energy parameter of $100 \mathrm{~mJ}$ provided the greatest $\Delta \mathrm{T}$ mean, for $2 \mathrm{~mm}$ thickness (10.20 \pm $\left.3.56^{\mathrm{A}}\right)$ and for $1 \mathrm{~mm}\left(11.00 \pm 3.46^{\mathrm{A}}\right)$, differing significantly from the energy parameters of 80 and $60 \mathrm{~mJ}$. For the energy parameter of 80 and $60 \mathrm{~mJ}$, there was no significant difference. 
It is noteworthy that the variation of temperature for $1 \mathrm{~mm}$ of dentin thickness $\left(80 \mathrm{~mJ}=6.60 \pm 3.13^{\mathrm{B}} ; 60 \mathrm{~mJ}=6.20 \pm\right.$ $\left.1.79^{\mathrm{B}}\right)$ presented slightly higher than $2 \mathrm{~mm}(80 \mathrm{~mJ}=4.40 \pm$ $\left.0.89^{\mathrm{B}} ; 60 \mathrm{~mJ}=3.40 \pm 0.54^{\mathrm{B}}\right)$, but without statistical significance. In this condition, the temperature at $1 \mathrm{~mm}$ of thickness becomes critical to the tissues, while $2 \mathrm{~mm}$ presented a temperature increase lower than the boundary temperature. In agreement with a previous study [18], intrapulpal temperature increases induced by $\mathrm{Nd}$ :YAG laser are capable of causing damage to the pulp in dentin with a remaining thickness less than $1.0 \mathrm{~mm}$, especially without simulated pulpal pressure. As the absence of fluid is a non-vital condition, the variation of temperature would have no impact to the pulp. However, it is necessary to assess the effect of raising the temperature on the periodontal and adjacent tissues.

Thus, the results of this study demonstrated that the effect of the laser energy parameters on $\Delta \mathrm{T}$ was statistically significant. The higher laser energy parameter resulted in higher $\Delta \mathrm{T}$, in accordance with the literature $[6,12,30,31]$. Then, the third null hypothesis - changes in Nd:YAG laser energy parameters do not result in a significant influence on the intrapulpal temperature-was rejected.

More laboratory and clinical research is necessary to verify the bond strength of this technique on different thickness under pulpal pressure simulation and to evaluate the thermal effects of this methodology on the periodontal tissues.

\section{Conclusions}

Based on the current study, it can be concluded that:

- The dentin thickness did not interfere on the variation of intrapulpal temperature.

- Intrapulpal pressure simulation significantly reduced the $\Delta \mathrm{T}$ during laser irradiation on dentin substrate.

- The Nd:YAG laser energy parameters had a negative influence on the variation of temperature in the absence of PPS.

Acknowledgments The authors would like to thank CNPq/PIBIC/ UNESP for the financial support; Prof. Dr. Ivan Balducci for his assistance in statistical analysis; and Mr. Lucas Patto for his assistance with the diagram images.

\section{Compliance with ethical standards}

Conflict of interest The authors declare that they have no conflict of interest.

Ethical approval All procedures performed in studies involving human participants were in accordance with the ethical standards of the institutional and/or national research committee and with the 1964 Helsinki declaration and its later amendments or comparable ethical standards.
Informed consent Informed consent was obtained from all individual participants included in the study.

\section{References}

1. Goncalves SE, de Araujo MA, Damiao AJ (1999) Dentin bond strength: influence of laser irradiation, acid etching, and hypermineralization. J Clin Laser Med Surg 17:77-85

2. Matos AB, Oliveira DC, Navarro RS, de Eduardo CP, Matson E (2000) Nd:YAG laser influence on tensile bond strength of selfetching adhesive systems. J Clin Laser Med Surg 18:253-257

3. Franke M, Taylor AW, Lago A, Fredel MC (2006) Influence of Nd: YAG laser irradiation on an adhesive restorative procedure. Oper Dent 31:604-609

4. Steiner-Oliveira C, Ramalho KM, Bello-Silva MS, Aranha ACC, Eduardo CP (2012) The use of lasers in restorative dentistry: truths and myths. Braz Dent Sci 15:3-15

5. White JM, Goodis HE, Rose CL (1991) Use of the pulsed Nd:YAG laser for intraoral soft tissue surgery. Lasers Surg Med 11:455-461

6. Goodis HE, White JM, Marshall GW Jr, Yee K, Fuller N, Gee L, Marshall SJ (1997) Effects of Nd: and Ho:yttrium-aluminium-garnet lasers on human dentine fluid flow and dental pulp-chamber temperature in vitro. Arch Oral Biol 42:845-854

7. Schaller HG, Weihing T, Strub JR (1997) Permeability of dentine after Nd:YAG laser treatment: an in vitro study. J Oral Rehabil 24: 274-281

8. Matos AB, Oliveira DC, Kuramoto M Jr, Eduardo CP, Matson E (1999) Nd:YAG laser influence on sound dentin bond strength. J Clin Laser Med Surg 17:165-169

9. Oda M, Oliveira DC, Liberti EA (2001) Morphologic evaluation of the bonding between adhesive/composite resin and dentin irradiated with Er:YAG and Nd:YAG lasers: comparative study using scanning microscopy. Pesqui Odontol Bras 15:283-289

10. Araujo RM, Eduardo CP, Duarte Junior SL, Araujo MA, Loffredo LC (2001) Microleakage and nanoleakage: influence of laser in cavity preparation and dentin pretreatment. J Clin Laser Med Surg 19:325-332

11. Marimoto AK, Cunha LA, Yui KC, Huhtala MF, Barcellos DC, Prakki A, Gonçalves SE (2013) Influence of Nd:YAG laser on the bond strength of self-etching and conventional adhesive systems to dental hard tissues. Oper Dent 38:447-455

12. Silva TM, Gonçalves LL, Fonseca BM, Esteves SR, Barcellos DC, Damiao AJ, Gonçalves SE (2016) Influence of Nd:YAG laser on intrapulpal temperature and bond strength of human dentin under simulated pulpal pressure. Lasers Med Sci 31:49-56

13. Perdigao J, Swift EJ Jr, Denehy GE, Wefel JS, Donly KJ (1994) In vitro bond strengths and SEM evaluation of dentin bonding systems to different dentin substrates. J Dent Res 73:44-55

14. Garberoglio R, Brännström M (1976) Scanning electron microscopic investigation of human dentinal tubules. Arch Oral Biol $21: 355-362$

15. Marshall GW Jr (1993) Dentin: microstructure and characterization. Quintessence Int 24:606-617

16. Brännström M, Lindén LA, Aström A (1967) The hydrodynamics of the dental tubule and of pulp fluid. A discussion of its significance in relation to dentinal sensitivity. Caries Res 1:310-317

17. Sauro S, Pashley DH, Montanari M, Chersoni S, Carvalho RM, Toledano M, Osorio R, Tay FR, Prati C (2007) Effect of simulated pulpal pressure on dentin permeability and adhesion of self-etch adhesives. Dent Mater 23:705-713 
18. White JM, Fagan MC, Goodis HE (1994) Intrapulpal temperatures during pulsed Nd:YAG laser treatment of dentin, in vitro. $\mathrm{J}$ Periodontol 65:255-259

19. Lizarelli RF, Moriyama LT, Bagnato VS (2006) Temperature response in the pulpal chamber of primary human teeth exposed to Nd:YAG laser using a picosecond pulsed regime. Photomed Laser Surg 24:610-615

20. Ozök AR, Wu MK, De Gee AJ, Wesselink PR (2004) Effect of dentin perfusion on the sealing ability and microtensile bond strengths of a total-etch versus an all-in-one adhesive. Dent Mater 20:479-486

21. Michida SM, Passos SP, Marimoto AR, Garakis MC, de Araújo MA (2009) Intrapulpal temperature variation during bleaching with various activation mechanisms. J Appl Oral Sci 17:436-439

22. Belli R, Sartori N, Peruchi LD, Guimarães JC, Araújo E, Monteiro S Jr, Baratieri LN, Lohbauer U (2010) Slow progression of dentin bond degradation during one-year water storage under simulated pulpal pressure. J Dent 38:802-810

23. Schmalz G, Hiller KA, Nunez LJ, Stoll J, Weis K (2001) Permeability characteristics of bovine and human dentin under different pretreatment conditions. J Endod 27:23-30
24. Zach L, Cohen G (1965) Pulp response to externally applied heat. Oral Surg Oral Med Oral Pathol 19:515-530

25. Secilmis A, Bulbul M, Sari T, Usumez A (2013) Effects of different dentin thicknesses and air cooling on pulpal temperature rise during laser welding. Lasers Med Sci 28:167-170

26. Cardoso MV, Moretto SG, Carvalho RC, Russo EM (2008) Influence of intrapulpal pressure simulation on the bond strength of adhesive systems to dentin. Braz Oral Res 22:170-175

27. Pashley DH, Carvalho RM (1997) Dentine permeability and dentine adhesion. J Dent 25:355-372

28. Türkmen C, Günday M, Karaçorlu M, Basaran B (2000) Effect of $\mathrm{CO} 2, \mathrm{Nd}: \mathrm{YAG}$, and ArF excimer lasers on dentin morphology and pulp chamber temperature: an in vitro study. J Endod 26:644-648

29. Cox CJ, Pearson GJ, Palmer G (1994) Preliminary in vitro investigation of the effects of pulsed Nd:YAG laser radiation on enamel and dentine. Biomaterials 15:1145-1151

30. Yu D, Powell GL, Higuchi WI, Fox JL (1993) Comparison of three lasers on dental pulp chamber temperature change. J Clin Laser Med Surg 11:119-122

31. Srimaneepong V, Palamara JE, Wilson PR (2002) Pulpal space pressure and temperature changes from Nd:YAG laser irradiation of dentin. J Dent 30:291-296 